\title{
The Ten-Year History of the Asklepios Study
}

\section{An Interview with Professor Ernst R. Rietzschel, Primary Investigator and Leader of the Asklepios Study}

Jeong Bae Park

Department of Medicine/Cardiology, Cheil General Hospital, Dankook University College of Medicine, Seoul, South Korea

\begin{abstract}
The Asklepios study started 10 years ago when 2,500 subjects were screened between 2002 and 2004. And all of the $90+$ publications we have for the moment are from those cross-sectional data. This is called round 1 . Since 2011, in round 2, all of those patients have started to come back for a 10-year follow-up. At this moment, approximately 1,750 of those patients have been seen. The patients were followed by general practitioners (GP), and the GP again provided the information about what has happened with the medical status in the past 10 years including drug therapy: not only the drugs that they are taking at the moment were evaluated, but, because patients often use many drugs, the chronicles of drugs for major risk factors, for hypertension, lipids, contraceptives and more. Then, patients come to the study center where the same cluster of examinations are undertaken by one single doctor, Prof. Ernst R. Rietzschel and one study nurse, just like 10 years ago. Again, using a single observer at the two time frames has kept the methodology very strict.

\section{Curriculum Vitae}

Prof. Ernst R. Rietzschel, MD, PhD is a clinical cardiologist working at Ghent University, Ghent, Belgium, where he also holds a position as associate professor. His primary interest is in the field of prevention of cardiovascular diseases. His main scientific work for the past 14 years has been (and is) as the primary investigator and leader of the Asklepios study.

This study is a successful cooperation of several research groups of Ghent University with expanding links to other European and international research groups. The study has been following a random population sample of 2,524 subjects

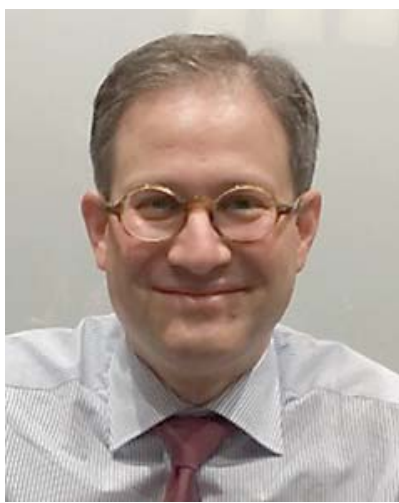

Prof. Ernst R. Rietzschel. 
Park: The Ten-Year History of the Asklepios Study

(with an average age of 45 years in 2002) for more than 10 years. One of the key strengths of the study is its breadth, encompassing both advances in primary care (the study was performed with the participation of 89 general practitioners), (epi)genetics, advanced cardiac hemodynamical modeling and biomarker profiling. Ultimately, the long-term Asklepios goals are better risk prevention strategies as well as a better understanding of cardiovascular function and successful human aging.

Prof. Rietzschel is the recipient of a number of scientific awards (including the Young Investigator Award of the European Society of Cardiology and the Career Development Award from the international Artery Society). He is also author of 95 peer-reviewed papers (of which $>75 \%$ are published in the top 25\% impact journals in the field) and reviewer for more than 15 international peer-reviewed scientific journals.

\section{Interview}

\section{Background}

J.B.P.: What is the purpose and background of your study?

E.R.R.: The purpose is to find better ways to predict cardiovascular risk and better ways to motivate people to reduce their risk whether it is through drugs or lifestyle. The ultimate goal is better risk prediction models and better risk management.

\section{What to Measure and How?}

J.B.P.: What are you measuring - vascular function and cardiac function and structure?

E.R.R.: The idea from the beginning was that we wanted to have a very good measurement of cardiovascular function, not just cardiac or vascular function. We have applanation tonometry of the carotid, femoral, brachial, and radial arteries. We have distension curves at the carotid and femoral arteries. And then we have flow at the carotid and femoral arteries but also in the proximal aorta, left ventricular outflow tract (LVOT). And then we have comprehensive 2D and 3D echo of the heart.

J.B.P.: So then how do you measure these on a patient in sequence?

E.R.R.: There are two halves of the examinations. The patient comes into the examination room and sees the study nurse first. She looks at the questionnaire, which has 30 pages of questions on family history, diet, physical activity, job stress and description, amount of hours sitting in front of a screen, etc. Then we do bioimpedance measurements and blood pressure measurement 3 times on the left side and 3 times on the right side (blinded), with 1 min in-between each measurement. Then, we get ECG and blood samples. Then, they do lung function testing and then we give the subjects an explanation on sleep apnea monitoring whilst they enjoy a cup of (caffeine free) tea or coffee. These are the first $45 \mathrm{~min}$.

And then they come into my room. I start with 2D classic cardiac echo and 3D cardiac echo. Then, they get an ultrasonography of the carotid and femoral arteries. We measure intima-media thickness (IMT), plaque and distension. And then I put on a continuous blood pressure measurement cuff (Nexfin). While the patient is lying down and the continuous blood pressure monitoring (CBPM) is running, I then do the tonometry with the Millar applanation tonometer at the carotid, femoral, radial, and brachial artery. Then, we measure their maximal grip strength (also lying down, CBPM running). Once that is done, they lie on their left side and we give them the handgrip device and let me grip at a quarter of their maximum strength. Because of this isometric exercise, their blood pressure is going up. And when they start feeling the stress in their arm, I tell them to give me a signal, and then I redo some of the cardiac echo measurements, flow measurements, and tonometry. I do a transmitral flow for diastolic function, a high frame rate 2D echo of the complete heart so that echo tracking and 
Park: The Ten-Year History of the Asklepios Study

strain and strain rate imaging is possible, a high frame rate 2D image with tissue velocity imaging (TVI) overlay to do tissue Doppler imaging, and I measure the flow in the LVOT. So that is the transmitral flow, 2D of the entire heart with and without TVI overlay and flow in the LVOT. This takes about $40 \mathrm{~s}$ to $1 \mathrm{~min}$. And then they lie down while continuing their submaximal handgrip. I measure the flow in the femoral artery. This allows us to have pulse wave velocity not only at rest but also pulse wave velocity when their blood pressure is higher. Finally, I perform the tonometry of the carotid artery. So that is $2 \mathrm{~min}$ in total and the exam is finished.

\section{Vascular Function in Relation to Cognitive Function and Aging}

J.B.P.: Can you explain why you think there is some connection between cognitive function and vascular dysfunction?

E.R.R.: There is a circumstantial link. There are a lot of the risk factors, for example, that are common to atherosclerosis and arterial stiffening, and that are the same risk factors for cognitive decline. That does not mean that it is causal, but it certainly is a possibility. Then, there is this intriguing possibility that if you have stiffer arteries, you also have more pressure and energy propagating pressure towards the cerebral (micro)vasculature. So you might have small vascular lesions. Arterial stiffening seems to be linked to the deep white matter lesions which are, however, not very specific. But there is certainly this possibility for a mechanistic link. Increased pulse pressure, which increases the hemodynamic load, cannot do good things on your brain vasculature in the long term. So there is certainly a common soil of risk factors and there are very plausible mechanisms.

J.B.P.: Have you ever read the paper on vascular aging continuum by Michael O'Rourke? It says there is pulse wave encephalopathy. Pulse wave may influence white matter legions or dementia. Do you think pulse wave can influence cognitive function?

E.R.R.: Yes, I think there certainly is a point. Arterial stiffening and cognitive decline seem to have a link - more than simply shared risk factors. It is very likely that there is a mechanistic link as discussed above.

J.B.P.: When the heart pumps, there occur 3 major fluctuations: pressure, flow and diameter changes. Pulse wave velocity is just a speed of the regional artery, such as a diseased artery with arterial calcification and fibrosis. So what do you think is the major mechanism of pulse wave velocity in the brain or fluctuation of pulse pressure? They are different.

E.R.R.: Yes, they are, but all could of course lead to cognitive decline. Pulse wave velocity is a marker of the health of your arteries and how resistant they will be and how fragile they will be. And then the pulsatile force is a direct force which is acting on those arteries, which is linked to arterial stiffness and which of course can accelerate the process. So, arterial stiffening by whatever mechanism is highly likely to be linked to cognitive decline.

J.B.P.: In the US, Prof. Edward G. Lakatta proposed 4 major parameters of vascular function to detect vascular aging. Carotid IMT or plaque, endothelial function, augmentation index, and pulse wave velocity. What is your personal opinion on this?

E.R.R.: I think it makes a lot of sense to not look at any single phenotype. I would go even further, and those are the studies we did in collaboration with Julio Chirinos from Pennsylvania and Patrick Segers at our own Ghent University. One of the most important advances Asklepios has generated is integrated cardiovascular function assessment where you have function of the heart and vascular function combined in a time-varying analysis. Those studies are the ones that are teaching us the most. Actually you only need pressure, flow and diameter well measured at key sites and you can hemodynamically describe the cardiovascular system quite well. I am not sure if the augmentation index is ideal parameter. It is very easy to measure this index purely on pulse wave. Our analyses with wave reflection, with wave separation analysis where you also need flow through the LVOT seem to yield more robust, powerful 
Park: The Ten-Year History of the Asklepios Study

markers. And they seem to better predict outcome than the augmentation index. Although both measure wave reflection, the fact that the augmentation index purely relies only on a pressure curve, is a handicap. It is difficult to get the timing right - where the wave reflection starts. So, that is something that is inherently logical that if you combine two (or more) signals, you are capturing far more information. You can then have parameters that are far more refined and potent. And wave reflection or reflection magnitude by wave separation analysis is a more outcome-predictive parameter than the augmentation index.

J.B.P.: How about measuring central pulse pressure? Maybe it is more sensitive than the augmentation index. The measurement of central systolic pressure, I know, is covered by medical insurance in the US.

E.R.R.: Yes, central pressure is the pressure which is acting on those arterial beds which are responsible for cardiovascular disease, but it is only one parameter. If you integrate the assessment, if you have carotid tonometry, flow over the LVOT, if you have diameters, then you have all the parameters in the system and derive the augmentation index and automatically have central pressure. But the fact that you can do these time-varying analyses is something far more potent. The heart does not 'see' blood pressure or arteries. The heart senses 'wall stress' throughout the cardiac cycle. The peak wall stress of the heart occurs actually very early in systole long before we get wave reflections. And so, we have peak wall stress at that moment in time and wave reflections are not part of that story. Central pulse pressure will be part of that story. Wave reflections come in later at the moment when the heart is partially emptied. They come in at the moment when the heart does not want to see wall stress. Wall stress at that late systolic time frame results in decreased systolic and diastolic function, and we believe, ultimately in heart failure. So it is when these forces act on each other throughout the cardiac cycle. The real step forward, I think, are these time-varying analyses where you can really understand the interaction between the heart and the vessels throughout a cardiac cycle. There is no one factor that captures all that information. You need to be more integrative.

\section{Epigenetics and Vascular Function}

J.B.P.: Tell me more about the genetic and lifestyle background of arterial stiffness and function, such as about telomere length.

E.R.R.: Telomere length is an epigenetic marker. Telomeres are the end fragments of your chromosome. And with each cell division, you lose a fixed length of your telomere cap because you cannot replicate a complete chromosome completely until the end. And so, the telomere shortens with the number of cell divisions you have. And so, if you have the need for more cell divisions, for example, because you have more oxidative stress, more cell damage, that would accelerate your telomere shortening. There is a very simple idea that was postulated 10-15 years ago, namely, that you are born with a certain telomere length, so maybe you inherit a fixed number of cell divisions your cells are going to have. So, if you are born with shorter telomeres, then you have less potential for cell divisions, and at a certain moment your cell divisions will 'run out' (called the Hayflick limit) and go into senescence: inherited short telomeres. That is a hypothesis that is not really likely anymore. There are no shorter telomeres in those who have a family history of cardiovascular disease, nor are there shorter telomeres in early stages of atherosclerosis. This is the work spearheaded by Sofie Bekaert and Tim De Meyer of the Asklepios study. A second hypothesis is that your telomeres by themselves are not causal for cardiovascular disease but the same factors that damage your arteries also damage your telomeres. That is very much likely to be the case. There is a third hypothesis which is still very interesting. The telomeres we measure in the blood are telomeres of peripheral blood leukocytes from fast-dividing cells from germ lines. Those are not the telomeres you have in your tissues. The leukocyte telomere length will not mirror the telomere 
Park: The Ten-Year History of the Asklepios Study

length you have in your muscle, which is not a dividing tissue. So it is a completely different biology. But there is this hypothesis that if you have longer telomeres, you have more pluripotent stem cells. And those stem cells are of course necessary for continuous repair both at the vascular level and for making sure that the plaque disruption is less likely. So, there is a possibility of blood borne link through that. So, there are three very good hypotheses, of which one seems unlikely, one is almost certain, and one is awaiting confirmation. The first longitudinal studies with repeat telomere measurements came out several years ago. And to the shock and surprise of the scientific world, we expected to see telomere shortening in everybody, and in some people it will go fast and in some people it will go slower, and those with faster telomere shortening probably have a high risk factor burden. But what we did not expect to find is telomere elongation in a substantial number of the general population.

J.B.P.: Tell me more about telomeres and telomerase or other parts of the DNA story.

E.R.R.: Telomere shortening limits the number of cell divisions which is a primary mechanism of the body for cancer prevention. Telomerase is active in germ cells making these cells immortal. If your telomerase is (over)active, except in germ cells, that is a mechanism for cancer development. However, it is probably a far more intricate system than we thought. I think if there is a potential in telomere length it is probably in the study of telomere attrition rate over time. That may still represent a potent biomarker of accumulated damage over time; a bit like hemoglobin A1C, but with a 10-20 times longer time frame. Not measuring glucose exposure but measuring oxidative stress exposure. So there might be a story there.

The other part of the DNA that we are really interested in is DNA methylation. DNA methylation is a mechanism by which the body silences genes. We start out with one cell. And that divides into skin cells, but also cardiac myocytes. All of these cells have the completely same genome. The reason one cell becomes a hair and another becomes heart muscle cell is because $90 \%$ of your genome is silenced. It is not active, not transcribed, so not making proteins so you get different phenotypes. That silencing mechanism is by methylation. If you methylate parts of the gene, they cannot be transcribed. It cannot be active. And if you are looking simply at DNA and genetics, you are measuring gene variations, but a lot of those gene variations will be in genes, which might not be active. So if you combine that with methylation, with methylomics, then you can focus on those gene variations that you see but also on the methylation differences you see. It might be that you do not need to alter the genetic code of a gene to make it behave differently. If you silence the gene, the genetic code will be exactly the same, but simply because it is methylated, it will lose its activity. Or if there is less methylation, it will regain its activity. So, I think methylation, methylomics, really might give us a higher level of insight on the genetics because you go beyond the code, you are looking more at functional effects of the genome.

\section{Lifestyle and Arterial Function}

J.B.P.: I remember you also look into the markers of lifestyle such as smoking and others.

E.R.R.: Yes, we have smoking of course, second-hand smoking, leisure time physical activity, physical activity at work, alcohol intake, a quite extensive semiquantitative food frequency questionnaire. So, they have to score for food 30 items. I think we are massively underestimating the effect of lifestyle. If there is one thing as a clinician that I have learned from the recent genetic papers, it is that lifestyle is important.

J.B.P.: So what is the result? What is bad for vascular function?

E.R.R.: Everything we have been telling patients for years. Nothing new: if you do not move, not good. Obesity is not good, eating bad stuff is not good. If you smoke, that is very bad. We could show it on the telomere length that the number of lifestyle parameters negatively impacts the telomere length, reflecting DNA damage. You could show it on IMT, presence of plaque, pulse wave velocity. It is simply there. And very often in the analysis, it is masked. 
Park: The Ten-Year History of the Asklepios Study

Because, if you are looking at lifestyle parameters, you are obviously taking into account classic risk factors. So, if you are doing a multivariate analysis, you are taking into account blood pressure and LDL cholesterol levels. But of course these factors themselves are already partially influenced by lifestyle. So you are taking away a large part of the potential for lifestyle to show up as a significant predictor in the models. Lifestyle is really important and the reason is that it exerts its effect throughout your life. It is acting on a very long time frame. Lifestyle is usually a habit, trait, an attitude to healthy behavior. It is not something you can change easily. That is something we - regrettably - know very well. Lifestyle has small effects, for example it changes blood pressure by a few $\mathrm{mm} \mathrm{Hg}$, but this small effect, when active over 30-40 years, can and will have a very large impact. We of course have no randomized clinical trial data to model this, but the genetic data, showing the impact of small changes in risk factors over a lifetime are a perfect model to try to understand how important lifestyle is.

J.B.P.: Ten years is quite long for the Asklepios study. So the long exposure of high blood pressure in vessels induces alterations in vascular function and structure. What happens if diabetes occurs in patients with high blood pressure during 10 years? Depending on the problems such as diabetes, dyslipidemia or smoking, will they differently affect the vascular function? I think the results may not be similar.

E.R.R.: True. Risk factors have different effects. For example, for blood pressure there seems to be a higher prevalence of carotid atherosclerosis and less femoral atherosclerosis. Smoking is more prone to femoral atherosclerosis and less to carotid atherosclerosis. Lipids are less implicated in arterial stiffening. But very highly implicated in everything else which is atherosclerosis. So all of these factors are insults to your vascular cell and your endothelial cell. But these are different insults and they result in different adaptations. But they are all additive and cumulative!

\section{Intermediate Phenotype and Hard Endpoint - Mismatch}

J.B.P.: There are some people who have very serious problems in the vascular function but live longer than young patients with healthier vascular function. Why do you think there is a mismatch between intermediate vascular phenotype and hard clinical events?

E.R.R.: The function tests are very partial and incomplete and specific. We have no good function test which can measure it all. Let me illustrate this part of the answer. For example, IMT is usually studied in the common carotid artery. But you usually do not see plaques in the common carotid. You see them as soon as bifurcation starts. You lose laminar flow and you get perturbed flow. So you can have perfectly normal IMT in the common carotid, and then go $5 \mathrm{~mm}$ further downstream to the bifurcation and you can have massive plaque. The second problem is that we are looking at 2 different diseases. The outcomes we are studying, stroke, myocardial infarction (MI), sudden death, is the result of plaque rupture with sudden thrombus. Atherothrombosis is not the same as atherosclerosis. If you have stable plaques, you will not have thrombus on top of them and you will not have a clinical event. You can have massive plaques which are highly calcified and perfectly stable that will stay asymptomatic throughout your life. But you can have a small plaque which is impossible to find but has a lipid-rich core with a thin fibrous cap and that can suddenly rupture and give you a massive stroke. So they are two different diseases. Atherosclerosis - arterial stiffening and atherothrombosis - clinical events. Maybe there are three because atherosclerosis and arterial stiffening are probably not the same diseases, so there are two to three different diseases. Your intermediate phenotypes are only looking at a part of 'vascular health' and do not give you the big picture. And thirdly, we should never use the word screening in cardiovascular disease. Because the disease you have is something you suddenly have if you look at the outcomes: stroke and MI. You are either not having a stroke or suddenly having stoke. There is no real lag time. It is not like cancer where you have cells that become cancerous and start to grow. 
Park: The Ten-Year History of the Asklepios Study

In cancer, you are looking at the disease itself when you do a test like mammography. You then have a gold standard (a biopsy) to prove the presence or absence of the disease. But in cardiovascular disease, there is no gold standard to know whether someone has cardiovascular disease before an event. The gold standard is when the patient is in the hospital and has had the event and is lucky enough to get to the hospital. And so, we are actually always dealing with risk percentages. So I think for me these are the three answers. The fact is that it is so difficult is a strong incentive to combine multiple indicators of vascular health and to see which ones add most to risk reclassification.

J.B.P.: Thank you for the wonderful talk.

\section{Acknowledgement}

I wish to thank our researcher, Eura Kim and Professor Sua Choi for the preparation of the manuscript and for the excellent review.

\section{References}

Bekaert S, De Meyer T, Rietzschel ER, De Buyzere ML, De Bacquer D, Langlois M, Segers P, Cooman L, Van Damme P, Cassiman P, Van Criekinge W, Verdonck P, De Backer G, Gillebert TC, Van Oostveldt P; Asklepios Investigators: Telomere length and cardiovascular risk factors in a middle-aged population free of overt cardiovascular disease. Aging Cell 2007;6:637-647.

Bossuyt J, Van Bortel LM, De Backer TL, Van De Velde S, Azermai M, Segers P, De Buyzere M, Van Daele C, Rietzschel E: Asymmetry in prevalence of femoral but not carotid atherosclerosis. J Hypertens 2014;32:1429-1434.

-Chirinos JA, Rietzschel ER, Shiva-Kumar P, De Buyzere ML, Zamani P, Claessens T, Geraci S, Konda P, De Bacquer D, Akers SR, Gillebert TC, Segers P: Effective arterial elastance is insensitive to pulsatile arterial load. Hypertension 2014;64:1022-1031.

-Chirinos J, Rietzschel E, De Buyzere M, De Bacquer D, Gillebert T, Gupta A, Segers P; Asklepios Investigators: Arterial load and ventricular-arterial coupling: physiologic relations with body size and effect of obesity. Hypertension 2009; 54:558-566.

-Chirinos J, Segers P, Gillebert TG, Gupta A, De Buyzere M, De Bacquer D, St. John Sutton M, Rietzschel ER; Asklepios Investigators: Arterial properties as determinants of time-varying myocardial stress in humans. Hypertension 2012;60:64-70.

-Chirinos J, Segers P, Rietzschel E, De Buyzere M, Raja M, Claessens T, De Bacquer D, St. John Sutton M, Gillebert TG; Asklepios Investigators: Early and late systolic wall stress differentially relate to myocardial contraction and relaxation in middle-aged adults: the Asklepios study. Hypertension 2013;61: 296-303.

-De Meyer T, Rietzschel ER, De Buyzere ML, Langlois MR, De Bacquer D, Segers P, Van Damme P, De Backer GG, Van Oostveldt P, Van Criekinge W, Gillebert TC, Bekaert S; Asklepios study investigators: Systematic telomere length and preclinical atherosclerosis: the Asklepios study. Eur Heart J 2009;30:3074-3081.

-Denil SL, Rietzschel ER, De Buyzere ML, Van Daele CM, Segers P, De Bacquer D, Van Criekinge W, Bekaert S, Gillebert TC, De Meyer T; Asklepios Investigators: On cross-sectional associations of leukocyte telomere length with cardiac systolic, diastolic and vascular function: the Asklepios study. PLoS One 2014;9:e115071.

-Hoebeeck L, Rietzschel ER, Langlois M, De Buyzere M, De Bacquer D, De Backer G, Maes L, Gillebert T, Huybrechts I: The relationship between diet and subclinical atherosclerosis: results from the Asklepios study. Eur J Clin Nutr 2011;65:606-613.

Langlois M, Rietzschel ER, De Buyzere ML, De Bacquer D, Bekaert S, Blaton V, De Backer G, Gillebert TC; Asklepios Investigators: Femoral plaques confound the association of circulating oxidized low-density lipoprotein with carotid atherosclerosis in a general population aged 35-55 years (Asklepios Study). Arterioscl Thromb Vasc Biol 2008;28:1563-1568.

O’Rourke MF, Adji A, Namasivayam M, Mok J: Arterial aging: a review of the pathophysiology and potential for pharmacological intervention. Drug Aging 2011;28: 779-795.

O’Rourke MF, Safar ME, Dzau V: The cardiovascular continuum extended: aging effects on the aorta and microvasculature. Vasc Med 2010;15:461-468.

Rietzschel E, De Buyzere M, Bekaert S, Segers P, De Bacquer D, Cooman L, Van Damme P, Cassiman P, Langlois M, Van Oostveldt P, Verdonck P, De Backer G, Gillebert T; Asklepios Investigators: Rationale, design, methods and baseline characteristics of the Asklepios study. Eur J Cardiovasc Prev Rehabil 2007;14:179-191. 
Singer J, Trollor JN, Crawford J, O’Rourke MF, Baune BT, Brodaty H, Samaras K, Kochan NA, Campbell L, Sachdev PS, Smith E: The association between pulse wave velocity and cognitive function: the Sydney Memory and Ageing Study. PLoS One 2013;8:e61855.

-Van daele CM, De Meyer T, De Buyzere ML, Gillebert TC, Denil SL, Bekaert S, Chirinos JA, Segers P, De Backer GG, De Bacquer D, Rietzschel ER; Asklepios Investigators: Addition of a novel, protective family history category allows better profiling of cardiovascular risk and atherosclerotic burden in the general population. The Asklepios Study. PLoS One 2013;8:e63185.

-Vermeersch S, Rietzschel ER, De Buyzere M, De Bacquer D, De Backer G, Van Bortel L, Gillebert TG, Verdonck P, Segers P; Asklepios Investigators: Age and gender related patterns in carotid-femoral PWV and carotid and femoral stiffness in a large healthy, middle-aged population. J Hypertens 2008;26:1411-1419. 